\title{
Flora do Ceará: Hydrocharitaceae e as fanerógamas marinhas: Cymodoceaceae, Ruppiaceae
}

Flora of Ceará: Hydrocharitaceae and marine phanerogams: Cymodoceaceae, Ruppiaceae

\author{
Lígia Queiroz Matias ${ }^{1,3}$, Hortência Helena e Silva Gonzalez ${ }^{2}$ \& Willer Rocha de Oliveira ${ }^{2}$
}

\begin{abstract}
Resumo
As áreas inundadas continentais e a região costeira do estado do Ceará apresentam comunidades vegetais aquáticas constituídas por Angiospermas. Espécies pertencentes às famílias Hydrocharitaceae, Cymodoceaceae e Ruppiaceae são comumente encontrados nestes ambientes, constituindo relvados marinhos ou de água doce, submersos ou emersos. Este trabalho apresenta o estudo florístico destas famílias, descrevendo representantes dos gêneros Apalanthe, Egeria, Najas, Limnobium, Halophila, Halodule e Ruppia, estes três últimos também reconhecidos pela denominação de "fanerógamas marinhas". Um total de nove táxons pertencentes à Hydrocharitaceae foram registrados para o Ceará: Apalanthe granatensis, Egeria densa, E. najas, Limnobium laevigatum, Najas arguta var. arguta, Najas arguta var. podostemon, N. conferta, N. marina e Halophila decipiens. Além destas, a ocorrência de Halodule wrightii (Cymodoceaceae ) foi registrada em toda a extensão litorânea, enquanto Ruppia maritima (Ruppiaceae) em áreas estuarinas. A maioria das espécies continentais registradas foi encontrada na região central semiárida do Estado do Ceará. Neste trabalho são apresentadas descrições, comentários taxonômicos, chaves de identificação, ilustrações e dados de distribuição geográfica das espécies.
\end{abstract}

Palavras-chaves: macrófitas aquáticas, ervas marinhas, áreas inundadas, comunidades vegetais interdidais.

\begin{abstract}
The continental wetlands and the coast of Ceará State included submerged and emmersed aquatic plant communities composed of Angiosperms. Species belonging to the Hydrocharitaceae, Cymodoceaceae and Ruppiaceae families are found in these environments, comprising vegetation of intertidal zones and freshwater marshes, submerged or emersed. This work presents a floristic study of these families in Ceará and descriptions of representatives of the genera Apalanthe, Egeria, Najas, Halophila, Halodule and Ruppia. The last three are known as "marine phanerogams or seagrasses". Nine taxa of Hydrocharitaceae were recorded: Apalanthe granatensis, Egeria densa, E. najas, Limnobium laevigatum, Najas arguta var. arguta, Najas arguta var. podostemon, N. conferta, N. marina and Halophila decipiens. In addition to these, Halodule wrightii (Cymodoceaceae) populations were found throughout the coast of the State while Ruppia maritima (Ruppiaceae) had occurrence reported only in estuaries. The majority of continental species were reported in a semi-arid central region of Ceará State. Full descriptions, taxonomic observations, identification keys, illustrations and data on geographic distribution are presented.
\end{abstract}

Key words: aquatic macrophytes, seagrass, wetlands, intertidal zone communities.

\section{Introdução}

Os representantes de Hydrocharitaceae Juss., Ruppiaceae Horan. e Cymodoceaeae Vines ocorrem em ambientes aquáticos continentais e marinhos. No estado do Ceará, as espécies compõem formações vegetais herbáceas muito evidentes durante o período chuvoso ou, no caso das espécies marinhas, perceptíveis com o recuo diário das marés.

Estas famílias pertencem às Alismatales R.Br. ex Bercht. \& J.Presl (APG IV 2016), porém com posicionamentos filogenéticos distintos. Hydrocharitaceae, Alismataceae Vent. e Butomaceae (Mirb.) constituem um grupo monofilético reconhecido como "clado petaloide"

\footnotetext{
${ }^{1}$ Universidade Federal do Ceará, Centro de Ciências, Depto. Biologia, Lab. Taxonomia de Angiospermas, bl. 906, Campus do Pici, 60440-900, Fortaleza, CE, Brasil.

${ }^{2}$ Universidade Federal do Ceará, Curso de Graduação em Ciências Biológicas, Centro de Ciências, Campus do Pici, 60440-900, Fortaleza, CE, Brasil.

${ }^{3}$ Autor para correspondência: lqmatias@ufc.br
} 
por apresentarem perianto provido de cálice e corola. Por outro lado, as Cymodoceaeae e as Ruppiaceae formam um grupo monofilético com as demais Alismatales (Aponogetonaceae Planch., Juncaginaceae Rich., Maundiaceae Nakai, Potamogetonaceae Berch. \& J.Presl., Scheuchzeriaceae F.Rudolphi, Zosteraceae Dumort.) evidenciadas pelo perianto tepaloide (Ross et al. 2016). Apesar da filogenia de Alismatales possuir uma segunda configuração na qual evidenciou um parentesco com as Acoraceae Martinov., as Hydrocharitaceae permaneceram posicionadas como grupo monofilético e irmão de Butomaceae, constituindo o "clado petaloide" (Petersen et al. 2016). Neste mesmo estudo, as Cymodoceaceae e as Ruppiaceae posicionaram-se distante filogeneticamente de Hydrocharitaceae, porém mantendo um "clado tepaloide".

Hydrocharitaceae Juss. está representada por 18 gêneros e aproximadamente 116 espécies (Stevens 2001), amplamente distribuídas em ambientes de água doce e marinhos tropicais e subtropicais. A origem oriental dos seus representantes foi inferida por Chen et al. (2012) ao considerar o sudoeste da Ásia como o centro de diversidade genética da família e ao fato de que, no Cretáceo, a região apresentou condições climáticas de elevada umidade e temperatura associadas à formações de planícies inundadas (Vu Khu 2000; Okada 2001).

Considerando a variação morfológica dos seus representantes, Hydrocharitaceae foi dividida nas seguintes subfamílias (Stevens 2001 em diante): Anacharidoideae Thomé, representada pelos gêneros Apalanthe Planch., Appertiella C.D.K.Cook \& Triest, Blyxa Noronha ex Thouars, Egeria Planch., Elodea Michx., Nechamandra Planch. e Ottelia Pers. com ocorrência em regiões temperadas e tropicais, especialmente na América; Hydrocharitoideae Eaton, por Hydrocharis e Limnobium, dispersos nas regiões temperada e subtropical; Hydrilloideae Luersson, por Enhalus Rich., Halophila Thouars, Hydrilla Rich., Najas L., Thalassia Banks ex C.Koenig e Vallisneria L. com ocorrência nas regiões tropical e subtropical, especialmente África e Ásia, sendo Najas subcosmopolita; e Stratiotoideae Luersson, por Stratiotes, restrito à Eurasia. Na América do Sul existe o predomínio de gêneros de água doce, enquanto que na Ásia e Oceania, os gêneros marinhos Enhalus, Halophila e Thalassia são mais representativos (Stevens 2001). No Brasil, Apalanthe, Egeria, Limnobium, Najas e Ottelia são indicados para áreas alagadas continentais e Halophila para as regiões litorâneas (BFG 2015), em profundidades que podem ultrapassar os $50 \mathrm{~m}$ (Oliveira et al. 1983).

Duas espécies do gênero Halophila, $H$. bailloni Aschers. e H. decipiens Ostenf., fazem parte do conhecido grupo das fanerógamas marinhas. Este grupo é formado por representantes de 12 gêneros das famílias Cymodoceaceae, Hydrocharitaceae, Posidoniaceae e Zoosteraceae, todas inseridas na ordem Alismatales. Evolutivamente, estas plantas representam diferentes linhagens que evidenciam uma possível ocupação secundária do ambiente aquático marinho, sendo estes eventos considerados singulares entre as Angiospermas, as quais tiveram sua história evolutiva predominantemente envolvida em ecossistemas terrestres (Les et al. 1997). As fanerógamas marinhas ocorrem nas regiões tropicais e temperadas (Green \& Short 2003), podendo constituir uma vegetação dominante em extensas áreas da zona litorânea brasileira (Oliveira et al. 1983).

O presente trabalho teve como objetivo o estudo florístico de Hydrocharitaceae e de fanerógamas marinhas, Cymodoceaceae e Ruppiaceae do estado do Ceará, contribuindo para o conhecimento da diversidade da flora local e atualização das informações de distribuição geográfica e de padrões de ocupação dos ambientes.

\section{Material e Métodos}

As amostras estudadas foram obtidas através de coletas realizadas nos anos de 2011 a 2015, assim como espécimes herborizados localizados nos herbários (ALCB, ASE, EAC, HCDAL, HVASF, UFRN, as siglas seguem Thiers, continuamente atualizado). A identificação das espécies foi realizada através de bibliografia especializada (Cook 1985, 1996, 1998; Cook \& Urmi-König 1983, 1984; den Hartog 2006; Lowden 1986, 1992; Haynes 1977; Haynes \& Holm-Nielsen 2001; Oliveira et al. 1983). As abreviações dos nomes dos autores estão de acordo com IPNI (2015). O material coletado foi herborizado seguindo a metodologia de Ceska (1986) e Haynes (1984) e depositado no herbário EAC. As formas de crescimento seguem Cook (1996). As descrições das famílias e gêneros estão baseadas em Cook (1985, 1998), Cook \& Urmi-König (1983, 1984), den Hartog (2006), Kubitzki (1998), Lowden (1986, 1992) e Oliveira et al. (1983). O sistema de quadriculas 


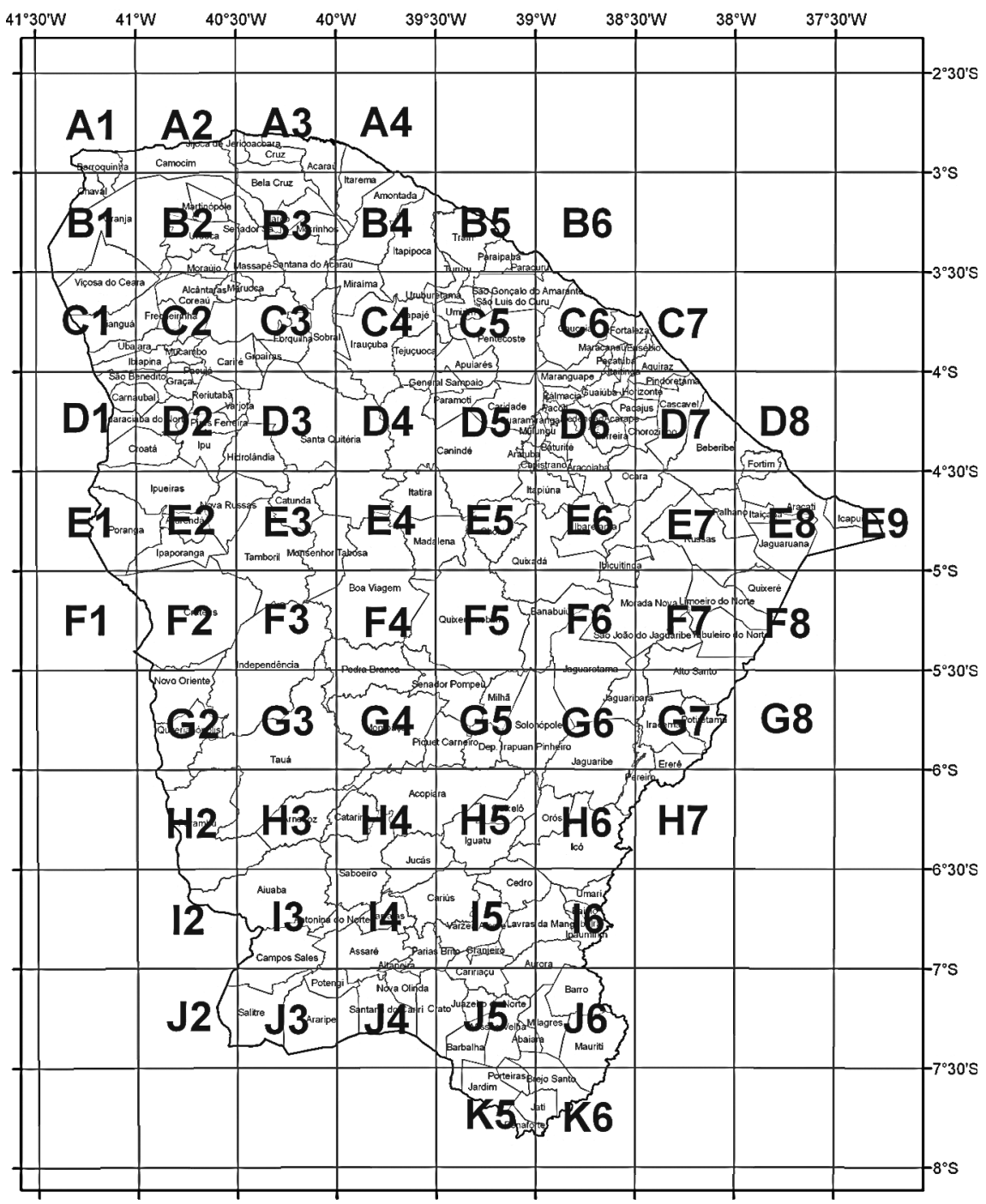

Figura 1 - Mapa do estado do Ceará (CE), Brasil, evidenciando o sistema de quadrículas georreferenciadas. Figure 1 - Map of Ceará state (CE), Brazil, showing the system of georeferenced squeres grid.

georreferenciadas com grade de $0,5^{\circ}$ foi utilizado para a distribuição geográfica das espécies (Fig. 1), o qual vem sendo tradicionalmente utilizado para a Flora do Ceará (Matias \& Souza 2011). A ocorrência das populações foi determinada através das coordenadas obtidas por GPS (em campo) ou com base nos dados de registro de Herbários.

\section{Resultados}

Tratamento taxonômico

\section{Chave de identificação de famílias}

1. Plantas submersas de ambiente marinho

1'. Plantas submersas ou emersas de ambientes aquáticos continentais

2. Folhas oblongas-obovadas, ovário ínfero

Hydrocharitaceae

2'. Folhas lanceoladas, ovário súpero

3. Ápice foliar bicúspide à tricúspide, flores díclinas Ruppiaceae 
Hydrocharitaceae Juss., Genera Plantarum: 67 (1789).

Plantas monoicas ou dioicas, herbáceas aquáticas, submersas ou emersas, livres flutuantes ou enraizadas. Raízes adventícias na região nodal caulinar. Caule monomórfico ou dimórfico, rizomatoso, horizontal com folhas escamiformes, clorofilado longo, ereto ou prostrado; entrenós curtos distais a longos proximais ou regulares. Filotaxia alterna, oposta ou verticilada. Folhas simples, uninérveas ou paralinérveas, geralmente com margem serreada, bainha aberta; lígula ausente; estípulas comumente ausentes; escamas intravaginais inconspícuas ou escamiformes. Inflorescência cimosa ou reduzida a uma flor solitária axilar. Flores díclinas ou monóclinas, monoclamídeas ou diclamídeas, trímeras, pétalas e sépalas livres; estames 3-numerosos, livres ou unidos entre si, anteras rimosas; gineceu gamocarpelar, 3-6 carpelar, ovário ínfero, unilocular, unipluriovulado. Fruto baga ou cápsula.

\section{Chave de identificação dos gêneros de Hydrocharitaeae do Ceará}

1. Plantas marinhas, folhas oblonga-obovadas 5. Halophila

1'. Plantas aquáticas continentais; folhas lanceoladas a lineares ou pecioladas elípticas a orbiculadas.

2. Caule incumbente emerso; filotaxia polística com entrenós curtos formando rosetas apicais, estípulas presentes, pecíolo ereto 1. Limnobium

2'. Caule flexível submerso; filotaxia alterna, oposta ou verticilada; folhas dispostas por todo caule, estípulas e pecíolo ausentes.

3. Folhas com bainha; flores aclamídeas 3. Najas

3'. Folhas sem bainha; flores monoclamídeas ou diclamídeas.

4. Plantas monoicas; folha linear triangular com estrias fibrosas marginais ... 4. Apalanthe

4'. Plantas dioicas; folha lanceoladas sem estrias fibrosas marginais 2. Egeria

\section{Limnobium Rich.}

1.1. Limnobium laevigatum (Humb. \& Bonpl. ex Willd.) Heine, Adansonia 8 (3): 315. 1968.

Fig. 2a-c

Plantas monoicas, herbáceas de água doce, emersas, livres flutuantes ou enraizadas. Raizes adventícias basais. Caule monomórfico, estolonífero incumbente flutuante, $2-3 \mathrm{~mm}$ diâm, entrenós $7-8 \mathrm{~cm}$ compr. Filotaxia alterna polística com entrenós curtos apicais compondo rosetas. Folha peciolada, pecíolo ereto 3,5-10 mm compr.; elíptica ou orbiculada, $4-7,5 \times$ 2-3,4 mm, ápice obtuso a agudo, base atenuada a aguda, acródoma, 7-nervada, margem lisa; bainha 1-1,5 cm compr.; estípulas presentes; escamas intravaginais lanceoladas, 1,2-2,3 mm compr. Inflorescências cimosas, pedúnculo 4,5-5 cm compr.; espata 1,7-2,5 mm compr., emersas. Flores díclinas, diclamídeas, trímeras, emersas, estaminadas e pistiladas desenvolvendo em ramos distintos do mesmo indivíduo, pediceladas; pedicelo $2,5-3 \mathrm{~cm}$ compr.; sépala ovada a lanceolada, $2-2,3 \times 3 \mathrm{~mm}$, verde; pétala lanceolada, $1-1,8 \times 1-1,3 \mathrm{~mm}$, brancas. Flor estaminada com 9 estames, 1,4-2,3 mm compr. Flor pistilada $8-10 \mathrm{mmm}$ compr., ovário ínfero, tricarpelar, unilocular, pluriovulado, estilete parcialmente diviso a $1 / 3$ da porção distal, 5-6 mm compr., estígmas 6, bífidos, Fruto cápsula non vidi.

Material examinado: Várzea Alegre, Lagoa Azul, 10.VI.2015, L.Q. Matias 741 (EAC); Cedro, Sítio MocóLages, 13.V.2015, L.Q. Matias 732 (EAC).

As populações de L. laevigatum possuem distribuição da América Central ao Norte da Argentina (Lowden 1992), ocorrendo em diferentes ambientes alagados, lênticos ou lóticos, naturais ou não (Cook \& Urmi-König1983). A distribuição geográfica de L. laevigatum no Brasil é bastante ampla, ocorrendo em todas as regiões e, para a Região Nordeste, os registros indicavam populações para Piauí, Pernambuco e Maranhão (BFG 2015). No Ceará, a espécie foi coletada pela primeira vez em 2015 , na região do Inhamuns (Fig. 1: I5), sendo este o único registro para o estado, representando uma nova ocorrência para espécie. As populações formam aglomerados densos em lagoas temporárias e pequenos açudes na região semiárida. A espécie pode ser facilmente reconhecida pelas folhas emersas orbiculares dispostas em rosetas apicais e inflorescências eretas com pétalas alvas. 


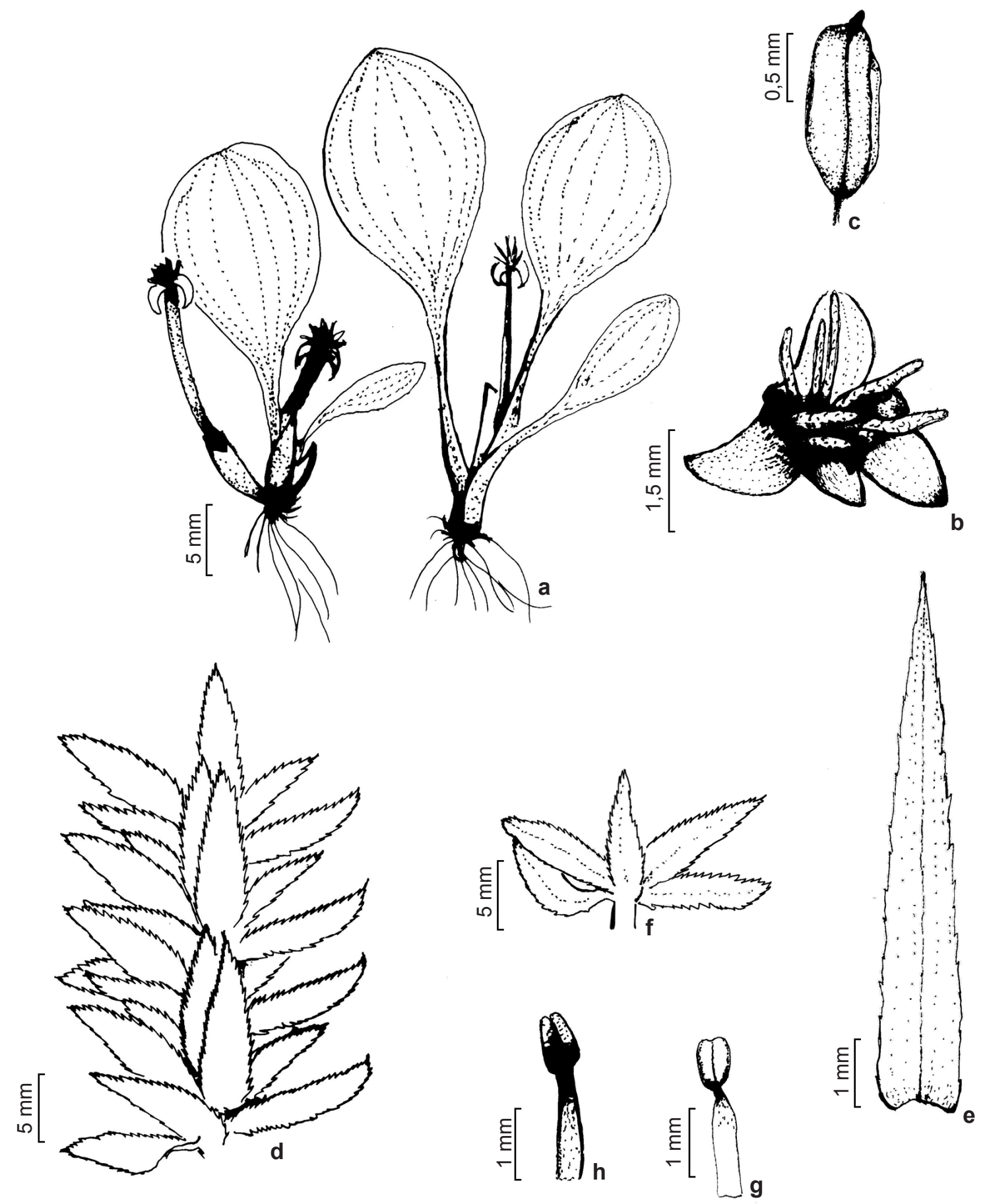

Figura 2 - a-c. Limnobium laevigatum - a. habito; b. flor pistilada; c. estame. d-g. Egeria densa - d. hábito; e. folha; f. detalhe do nó; g. filete clavado. h. E. najas - filete atenuado. [a-c. L.Q. Matias 741, 732 (EAC); d-f. C.A. Amorim 10650 (EAC); g. A.J. Rangel s.n. (EAC); h. (S.R. Lacerda s.n. 039527 (EAC)].

Figure 2 - a-c. Limnobium laevigatum - a. habit; b. pistillate flower; c. stamen. d-g. Egeria densa - d. habit; e. leaf; f. detail of node; g. clavate filament; h. E. najas - attenuate filament. [a-c. L.Q. Matias 741, 732 (EAC); d-f. C.A. Amorim 10650 (EAC); g. A.J. Rangel s.n. (EAC); h. (S.R. Lacerda s.n. 039527 (EAC)]. 
2. Egeria Planch., Ann. Sci. Nat. Bot. ser. 3, 11: 79. 1849.

Plantas dioicas, herbáceas de águas doces, submersas enraizadas. Raízes adventícias basais e na região nodal caulinar. Caule monomórfico, ereto, irregularmente ramificado e de fácil fragmentação, liso ou aculeado, entrenós inconspícuos curtos distais a alongados proximais. Filotaxia oposta ou verticilada, aglomeradas e sobrepostas nos ramos apicais. Folha séssil, linear-lanceolada, ápice agudo aculeado, base arredondada pela expansão da bainha, nervura paralelódroma, margem serreada não contornada por estrias fibrosas, acúleos inconspícuos unucelulares; bainha arredondada ou auriculada, serreada a denticulada, geralmente amplexicaule; estípulas ausentes; escamas intravaginais aos pares, triangulares a orbiculares, hialinas. Inflorescência cimosa escorpioide axilar com uma flor terminal, envolvida por espata séssil, estreita, ovóide, formada por 2 brácteas laterais conduplicadas. Flor díclina, diclamídea, emersa; sépala ovada, cimbiforme, verde; pétala ampla elíptica a orbicular, branca. Flor estaminada com 9 estames. Flor pistilada com 3 estaminódios, ovário ínfero, tricarpelar, unilocular, uniovular, 3 estiletes e estigmas distintos. Fruto cápsula hialina, irregularmente deiscente. Semente elíptica, testa lisa ou levemente ornamentada.

\section{Chave de identificação das espécies de Egeria do Ceará}

1. Caule com predomínio de 4 folhas por nó; filete clavado e com papilas na porção apicaL

2.1. Egeria densa

1'. Caule com predomínio de 5 folhas por nó; filete alongado e sem papilas na porção apical.

2.2. Egeria najas

2.1 Egeria densa Planch., Ann. Sci. Nat. Bot. ser. 3, 11: 79. 1849.

Fig. 2d-g

Caule $0,3-1$ mm diâm., entrenós $1,3-4,8$ $\mathrm{mm}$. Filotaxia verticilada, 4 folhas por nó. Folha lanceolada, $0,75-1,45 \times 2-4 \mathrm{~mm}$, minuciosamente serreada, espinhos multicelulares, margens sem fibras celulares. Flor estaminada axilar, sépalas $3,2,4-4 \times 1,2-2 \mathrm{~mm}$; pétalas 3, 5-9 × 3-6 mm; estames 9 , filete $2-3 \mathrm{~mm} \times 0,3-0,45 \mathrm{~mm}$, clavado na região apical, com papilas; nectários ca. $0,9 \mathrm{~mm}$ diâm, 0,5 mm altura, lobos iguais. Flor carpelada e fruto non vidi.

Material examinado: Caucaia, Lagamar do Cauípe, 27.IV.2013, D.L.S. Farias 48 (EAC). Crato, Açude Thomaz Ostene de Alencar, 18.IV.2012, A.J. Rangel (EAC 54030); Açude Thomaz Ostene de Alencar, 19.XII.2013, C.A. Amorim 10650 (EAC, HCDAL). Icapuí, lagoa Olho d'água, RPPN Fazenda Belém, 26.VI.2015, A.C. Albuquerque 93 (EAC). Iguatu, Santarém, 5.IX.2009, L.Q. Matias 594 (EAC). Juazeiro do Norte, 17.VII.2014, Açude Manoel Balbino, I.C. Lucena 10739 (EAC, HCDAL).

Material adicional examinado: BRASIL. PERNAMBUCO: Jatobá, Sítio Trindade Povoado Amburanas, 6.V.2003, L.Q. Matias 387 (EAC).

Egeria densa é considerada nativa nos estados da costa leste do Brasil e na Região Centro-oeste (Goiás) (BFG 2015). A sua área de ocorrência atinge as regiões de influência das bacias do rios Paraná e Uruguai, assim como as áreas inundadas do Uruguai e Argentina (Cook 1984). No Ceará, E. densa ocorre em lagoas temporárias ou podem formar densas populações nas margens dos reservatórios na região semiárida (Fig. 1: H5, J5). No litoral, as populações são comuns em lagamares e lagoas costeiras interdunares. A espécie é caracterizada por apresentar todos os estames com filetes clavados e papilosos na sua região anterior. Difere de $E$. heterostemon S. Koehler \& C.P. Bove (Holótipo RB!) que apresenta apenas três estames centrais com esta característica (Koehler \& Bove 2001).

2.2. Egeria najas Planch., Ann. Sci. Nat. Bot. ser. 3, 11: 80. 1849.

Fig. $2 \mathrm{~h}$

Caule 1,5 mm diâm., entrenós 0,5-3 mm. Filotaxia verticilada, 5 folhas por nó. Folha lanceolada, 1,1-1,45 cm compr., 3-3,5 mm larg., minuciosamente serreada, espinhos multicelulares, margens sem fibras celulares. Flor estaminada axilar, sépalas 3, 2-3mm compr., $1-1,5 \mathrm{~mm}$ de larg.; pétalas 3, 3,5-4,2 $\mathrm{mm}$ de compr., 2,5-2,9 mm de larg.; estames 9, filetes 1,5-1,9 mm compr., 0,2$0,4 \mathrm{~mm}$ de larg., atenuado e sem papilas na região anterior; nectário $0,5-0,7 \mathrm{~mm}$ diâm., $0,3-0,5 \mathrm{~mm}$ alt., lobos levemente diferenciados. Flor carpelada e fruto non vidi.

Material examinado: Crato, Açude Thomas Ostente de Alencar, 20.VI.2006, S.R. Lacerda (EAC 39527). 
Material adicional examinado: BRASIL. PERNAMBUCO: Cabrobó, Reservatório Tucutu, 2.VII.2008, N.B. Cavalcante 22 (HVASF, EAC). Salgueiro, Lagoa Norte, 1-Umãs, Lote 2, Serra do Livramento, 10.VII.2009, J.A. Siqueira-Filho 2249 (EAC, HVASF). RIO GRANDE DO NORTE, Parnamirim, Riacho Água Quente, Oliveira, 13.VIII.2008, A.C.P. Oliveira 13 (UFRN).

Na América do Sul, Egeria najas ocorre em simpatria com $E$. densa nas áreas inundadas das bacias dos rios Paraná e Uruguai (Cook 1984). A espécie é considerada nativa em oito estados brasileiros, nas regiões Sul (Paraná), Sudeste, Nordeste e Centro-Oeste (BFG 2015). No Ceará, a espécie é encontrada em lagoas temporárias nas regiões de clima semiárido (Fig. 1: J5). Egeria najas se diferencia de $E$. densa por apresentar todos os filetes não-clavados e desprovidos de papilas na sua região anterior. Por outro lado, E. najas se diferencia de E. heterostemon S. Koehler \& C.P. Bove por apresentar estames com filetes iguais, enquanto que $E$. heterostemon apresenta duas diferentes formas de filetes: clavados e papilosos nos estames periféricos e, nos estames centrais, os filetes são atenuados e glabros (Koehler \& Bove 2001).
3. Najas L., Sp. P1. 1015. 1753.

Plantas monoicas ou dioicas, herbáceas de águas doces, submersas enraizadas. Raízes adventícias basais e na região nodal caulinar. Caule monomórfico, ereto, irregularmente ramificado e de fácil fragmentação, liso ou aculeado, entrenós inconspícuos curtos distais a alongados proximais. Filotaxia alterna podendo assemelhar à oposta ou verticilada devido aos entrenós curtos. Folha séssil, linear-lanceolada, ápice agudo aculeado, base arredondada pela expansão da bainha, nervuras paralelódromas, margem serreada com espinhos multicelulares, geralmente contornada por estrias fibrosas; bainha arredondada ou auriculada, serreada ou ciliada; estípulas ausentes; escamas intravaginais inconspícuas. Flores díclinas, sésseis, aclamídeas, inconspícuas, solitárias, submersas, axilares em ramos apicais. Flor estaminada com um estame envolvido por bráctea hialina. Flor pistilada com ovário súpero, unicarpelar, unilocular, uniovular, 3 estiletes e estigmas distintos. Fruto aquênio envolvido por envoltório membranoso. Semente elíptica, ovada ou fusiforme, testa ornamentada.

\section{Chave de identificação das espécies de Najas L. do Ceará}

1. Plantas dioicas, caule aculeado, folhas com acúleos na venação central 3.1. Najas marina

1'. Plantas monoicas, caule liso, folhas sem acúleos na venação central

2. Sementes não recurvadas, testa reticulado-areolada 3.2. Najas arguta

2'. Sementes recurvadas, testa reticulado-estriada 3.3. Najas conferta

3.1. Najas marina L., Sp. P1., 2: 1015. 1753.

Fig. 3a-d

Plantas dioicas. Caule 0,6-1 mm diâm., entrenós apicais curtos formando adensamento de folhas, ca. $1 \mathrm{~mm}$, revestido por espinhos. Folha lanceolada, 1,9-2,6 × 1-2 mm, margem evidentemente serreada, estrias fibrosas marginais não aparentes, acúleos sobre a venação central; bainha levemente arredondada, tênue serreada, $3-5$ espinhos. Flor estaminada non vidi. Flor pistilada 3,2 mm compr. Fruto 1,9-2,4 $\times 0,3-0,5$ $\mathrm{mm}$. Semente elíptica, $1,8-2,1 \times 0,3-0,4 \mathrm{~mm}$ larg., não recurvada; testa reticulado-areolada, aréolas poligonais com limites tão longos quantos largos, dispostas em colunas irregularmente alinhadas.

Material examinado: Beberibe, lagoa permanente da Praia do Canto Verde, 25.VII.1999, L.Q. Matias 175 (EAC). Camocim, lagoa da Tatajuba, 27.IV.1998, L.Q. Matias 127 (EAC). Fortim, Nova esperança, 11.X.2011, H.H.S. Gonzalez 32 (EAC).
As populações de $N$. marina ocorrem do sul da Flórida à América do Sul (Lowden 1986). A distribuição geográfica de $N$. marina no Brasil é bastante esparsa, com registros no Nordeste apenas para Ceará, Piauí, Paraíba, Pernambuco e na Região Sudeste para o Rio de Janeiro e São Paulo (BFG 2015). No Ceará, a espécie está restrita a áreas alagadas da zona costeira (Fig. 1: A2, D7, D8), formando aglomerados densos em lagoas permanentes circundadas por carnaubais. Najas marina é a única espécie do gênero dióica e que apresenta acúleos no caule, tornando-se fácil diferenciá-la.

3.2. Najas arguta H.B.K., Nov. Gen. et Sp. PL., 1: 371. 1815.

Fig. $3 e-j$

Plantas monoica. Caule $0,6-0,8 \mathrm{~mm}$ diâm., entrenós apicais curtos formando adensamento de folhas, ca. $1 \mathrm{~mm}$, acúleos ausentes. Folha 


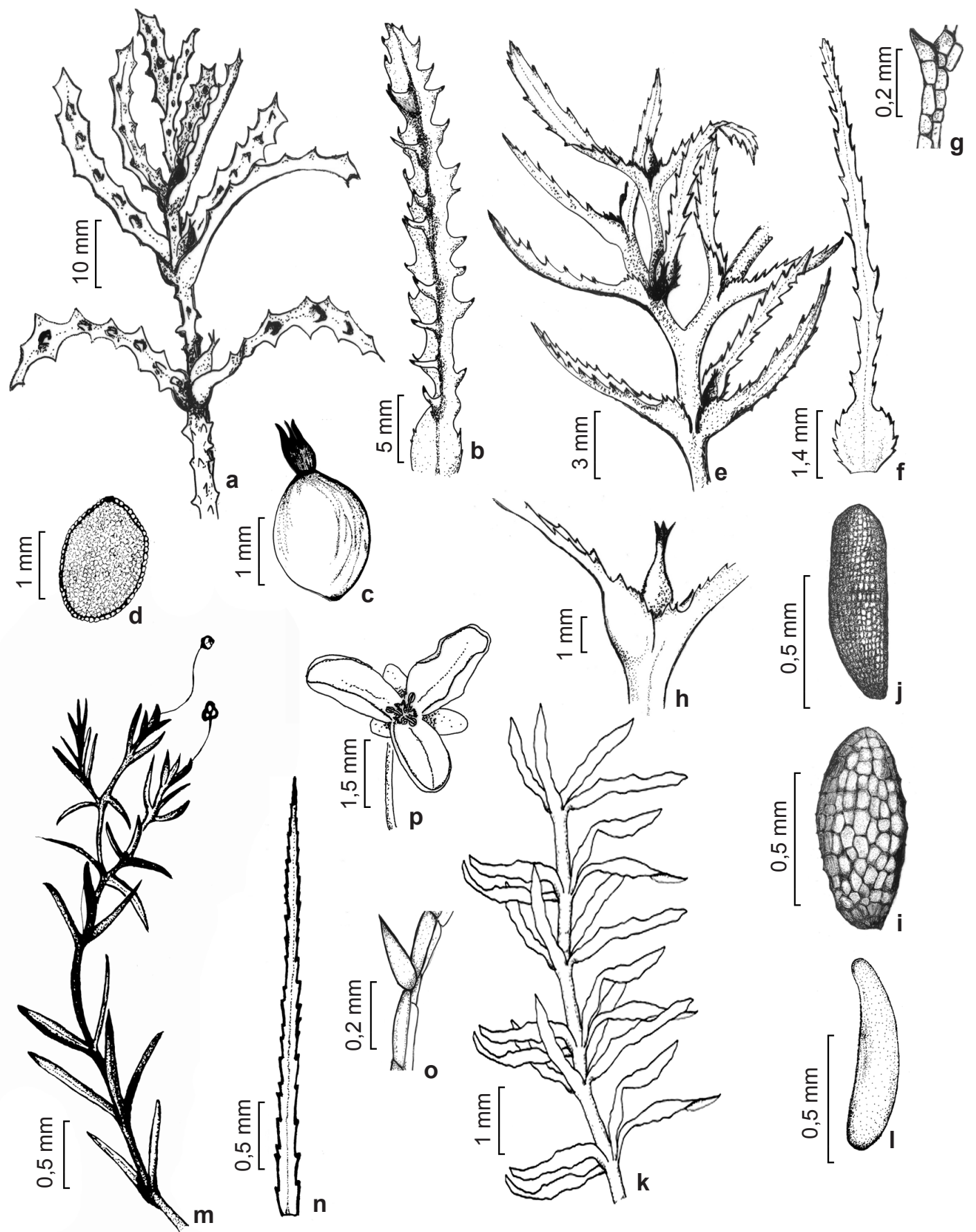

Figura 3 -a-d. Najas marina - a. hábito; b. folha; c. gineceu; d. semente envolvida por arilo. e-i. Najas arguta var. arguta - e. hábito; f. folha; g. detalhe da borda foliar; h. flor pistilada; i. semente. j. N. arguta var. podostemon - j. semente. k-1. Najas conferta - k. hábito; 1. semente. m-p. Apalanthe granatensis - m. hábito; n. folha; o. detalhe da borda foliar; p. flor. [a-d. H.H.S. Gonzalez 23 (EAC); e-i. H.H.S. Gonzalez 20 (EAC); j. M.A. Figueiredo 119 (EAC); k-1. A.S. Dias (EAC 54027); m-p. H.H.S. Gonzalez 23 (EAC)].

Figure 3 - a-d. Najas marina - a. habit; b. leaf; c. gynoecium; d. seed surronded by aril. e-i. Najas arguta var. arguta - e. habit; f. leaf; g. detail of leaf margin; h. pistilate flower; i. seed. j. N. arguta var. podostemon - j. seed. k-1. Najas conferta - k. habit; 1. seed. m-p. Apalanthe granatensis - m. habit; n. leaf; o. detail of leaf margin; p. flower. [a-d. H.H.S. Gonzalez 23 (EAC); e-i. H.H.S. Gonzalez 20 (EAC); j. M.A. Figueiredo 119 (EAC); k-1. A.S. Dias (EAC 54027); m-p. H.H.S. Gonzalez 23 (EAC)]. 
lanceolada, $10-30 \mathrm{~mm} \times 0,6-1,2 \mathrm{~mm}$, margem evidentemente serreada, estrias fibrosas marginais aparentes, acúleos sobre a venação central ausentes; bainha oblonga, completamente serreada, 6-12 acúleos. Flores estaminadas non vidi. Flores pistiladas $1-1,5 \mathrm{~mm}$ compr. Fruto $1,8-2,3 \times 0,4-0,5$ $\mathrm{mm}$. Semente oblongo-fusiforme, 1,5-1,6 × 0,4-0,6 $\mathrm{mm}$, não-recurvada; testa reticulada-areolada, aréolas conspícuas mais longas do que largas, dispostas em colunas regularmente alinhadas, compondo 14-36 colunas de aréolas.

Material examinado: Aiuaba, Estação Ecológica, 12.IV.1991, A. Figueiredo 119 (EAC); Mulungu, Estação Ecológica, 20.III.1991, A. Figueiredo 31 (EAC); 12.IV.1991, A. Figueiredo 119 (EAC). Crato, Lagoa da Cotia, 11.VI.2015, L.Q. Matias 742 (EAC); Açude Umari, 12.VI.2015, L.Q. Matias 743 (EAC). Independência, lagoa em BR-226, 12.V.2011, H.H.S. Gonzalez 20 (EAC). Quixeramobim, Encantado, 13.V.2011, H.H.S. Gonzalez 22 (EAC). Santa Quitéria, Fazenda Poço Vermelho, 9.V.2011, H.H.S. Gonzalez 04 (EAC).

Material adicional examinado: BRASIL. PERNANBUCO: Afrânio, Povoado Cabloco, 2.VI.2007, C.L. Seido 17 (HVASF).

Lowden (1986) sugeriu dois táxons infraespecíficos para a espécie: $N$. arguta var. arguta e N. arguta var. podostemon, considerando que estas apresentariam diferenças morfológicas nas sementes. Segundo o autor, N. arguta var. arguta apresenta sementes maiores e fusiformes, enquanto que $N$. arguta var. podostemon apresentaria sementes menores e oblongas. Porém a percepção desta variação torna-se difícil uma vez que os limites considerados pelo autor são tênues. Isto porque o autor considera que as sementes de N. arguta var. arguta possuiriam 1,6-2,8 mm compr. (comum 1,8-2,5 mm) e 24-36 (comum 28-32) linhas de auréolas, estas 2 a 3 vezes mais longas do que largas e com papilas nas paredes terminais; enquanto que $N$. arguta var. podostemon apresentariam sementes ca. 1,5-1,6 mm e 14-24 (comum 20) linhas de auréolas, estas com bordas iguais ou duas vezes mais longas do que largas (porém dificilmente quadrada) e sem papilas nas paredes terminais.

As sementes observadas nos espécimens de $N$. arguta do estado do Ceará apresentaram comprimento das sementes mais reduzido do que os indicados por Lowden (1986) (Fig. 3i, j). Porém, este dado contrasta com as informações obtidas de sementes analisadas de material adicional oriundo de Pernambuco [C.L. Seido 17 (EAC)], as quais exibiram um padrão semelhante ao descrito (2,8-3,1 mm).
Sendo assim, neste trabalho não consideramos o tamanho das sementes como um bom caráter taxonômico para a determinação das variedades de $N$. arguta. No entanto, as plantas que possuiam sementes com forma fusiforme (Fig. 3i), cuja testa apresentou auréolas alongadas e de fácil visualização das papilas nas paredes terminais foram identificadas como $N$. arguta var. arguta [H.H.S. Gonzalez et al. 20 (EAC); H.H.S. Gonzalez et al. 4 (EAC); L.Q. Matias 743 (EAC)]. E as populações de N. arguta var. podostemon [H.H.S. Gonzalez et al. 22 (EAC); M.A. Figueiredo et al. 119 e 31 (EAC); L.Q. Matias 747 (EAC)] apresentaram sementes com auréolas de formato alongado e com suas paredes terminais desprovidas de papilas (Fig. 3j).

As populações de $N$. arguta ocorrem na América Central e do Sul (Lowden 1986). No Brasil, apresentam distribuição disjunta nas regiões Norte (Amazonas), Nordeste (Ceará, Pernambuco e Bahia) e Sudeste (Rio de Janeiro) (BFG 2015).

A área de ocorrência das populações de $N$. arguta var. podostemon restringe-se ao estado do Ceará e do Maranhão, sendo o único taxon de Hydrocharitaceae endêmico do Brasil (BFG 2015). Todas as populações de $N$. arguta registradas para o Ceará ocorreram em lagoas temporárias da região semárida (Fig. 1: D4, F3, F5).

3.3. Najas conferta (A., Br.) A. Br., Sitzb. Ges. Naturf. Fr. Berlin 17. 1868; Bot. Zeit., 26: 510. 1868.

Fig. 3k,1

Plantas monoicas. Caule 0,6-0,8 mm diâm., entrenós apicais curtos formando adensamento de folhas, ca. $1 \mathrm{~mm}$, acúleos ausentes. Folha lanceolada, 2-3 × 0,5-1,3 mm, acúleos sobre a venação central ausentes, margem evidentemente serreada, geralmente com estrias fibrosas aparentes; bainha arredondada, completamente serreada, 10-12 espinhos. Flor estaminada non vidi. Flor pistilada 1-2 mm compr. Fruto 1,9-2,3 × 0,2$0,5 \mathrm{~mm}$. Semente oblongo-fusiforme, 1,7-2 $\times$ 0,2-0,4 mm, recurvada; testa aureolado-estriada, comprimento da aureola o triplo da largura, paredes anticlinais mais conspícuas do que as clinais, imprimindo uma ornamentação estriada dispostas em linhas regulares, compondo 20-31 alinhamentos de aréolas mais longas do que largas. Material examinado: Caridade, Lagoa Contendas, 5.VIII.2009, D.J.L. Souza (EAC 45467). Iguatu, Lagoa do Baú, 6.IX.2009, L.Q. Matias 592 (EAC); Lagoa do Gregório, 15.V.2010, L.R.O. Normando et al. 153 (EAC); Lagoa Paredão, 15.V.2010, L.R.O. Normando et al. 178 
(EAC); Lagoa do Saco, 24.X.2010, L.R.O. Normando et al. 504 (EAC). Lavras de Mangabeira, Açude de Quixadá, 27.VIII.2000, C. Oliveira (EAC 31308); Açude Rosário, 27.VI.2013, A.S. Dias (EAC 54027).

Najas conferta é restrita à América com registros para os Estados Unidos, Cuba, República Dominicana, Panamá, Bolívia e Brasil (Lowden 1986). No Brasil a espécie está presente nas cinco regiões e nos domínios fitogeográficos: Caatinga, Cerrado, Floresta atlântica, Pampa e Pantanal (BFG 2015). Os registros no estado foram em corpos d'água nas regiões de clima semiárido (Fig. 1: D5, H5, I5). O alongamento da semente e sua curvatura são características singulares de $N$. conferta.

4. Apalanthe Planch., Ann. Mag. Nat. Hist. ser. 2, 1: 87. 1848 .

4.1. Apalanthe granatensis Planch., Ann. Mag. Nat. Hist. ser. 2, 1: 87. 1848.

Fig. 3m-p

Plantas monoicas, herbáceas de águas doces, submersas enraizadas. Raízes adventícias basais e na região nodal. Caule monomórfico, ereto, 0,6-1 mm diâm., entrenós 3,5-8 mm. Filotaxia verticilada. Folha séssil, linear triangular, 0,5-1,1 cm compr., 0,2-0,6 mm larg., ápice agudo finalizando em acúleo simples, base truncada, nervura paralelódroma, margem serrilhada contornada por estrias fibrosas, espinhos unicelulares; sem estípulas; escamas intravaginais aos pares, elípticas, hialinas. Flor monóclina, diclamídea, trímera, séssil, solitária, axilar, emersa pela expansão do hipanto; brácteas basais aos pares; sépala oblonga, 1,5-1,8 × 0,6-0,8 $\mathrm{mm}$ larg., verde; pétala obovada, 3-3,4 × 1,8-2 $\mathrm{mm}$, branca; estames 3 , livres, antissepálos, 1,2 mm compr.; ovário ínfero, tricarpelar, unilocular, pluriovulado, estilete bífido. Fruto cápsula, 5-6 $\mathrm{mm}$, rostro ca. $1 \mathrm{~mm}$. Semente elíptica, testa esparsamente pilosa.

Material examinado: Aiuaba, Lagoa do Miguel da Estação Ecológica, 20.V.2003, L.Q. Matias 436 (EAC). Caridade, Lagoa Contendas, 6.VI.2009, A.B. Tabosa 48 (EAC). Granja, entrada para Santa Terezinha, 6.XI.2007, L.Q. Matias (EAC 43603). Iguatu, CE 060, 24.VI.2015, L. Ibiapina-Santos 40 (EAC). Independência, lagoa em BR 226, 12.V.2011, H.H.S. Gonzalez 21 (EAC). Mauriti, açude no Sítio Cabloco, estrada que liga Monte Horebe a Mauriti, 31.VII.2011, V.M. Cotarelli 12465 (HVASF). Santa Quitéria, Fazenda Poço Vermelho, 9.V.2011, H.H.S. Gonzalez 5 (EAC).

Material adicional examinado: BRASIL. PARAÍBA: São José das Piranhas, Lagoa do Alto da Serra, 8.IV.1999, Paes-Barreto 18 (EAC). PERNAMBUCO: Sertânia, Lagoa PE-280, 16.XII.2008, J. Antunes 31 (EAC). RIO GRANDE DO NORTE: Parnamirim, A.M. Marinho 101, 30.V.2009 (EAC).
Apalanthe granatensis é a única espécie do gênero e é amplamente distribuída na América do Sul (Cook 1985). Segundo BFG (2015), a espécie foi registrada em 18 estados brasileiros distribuídos nas regiões Norte, Nordeste, CentroOeste e Sudeste do país. No Ceará, a espécie pode ser encontrada em corpos d'água na margem de estradas ou em depressões nas regiões de clima semiárido do estado e em lagoas perenes costeiras (Fig. 1: B2, D3, D5, F3, I3, J6). Apalanthe. granatensis é diferenciada das demais espécies de Hydrocharitaceae pela presença de fibras celulares na margem foliar.

5. Halophila Thouars. Gen. Nov. Madagasc. 2: 2. 1806.

5.1. Halophila decipiens Ostenf. Bot. Tidsskr. 24(3): 260-261. 1902.

Fig. 4a-f

Plantas monoicas, herbáceas marinhas, submersas enraizadas. Raízes adventícias na região nodal caulinar. Caules dimórficos, rizomatosos horizontais com pares de escamas subopostas e eretos com pares foliares; rizoma $0,5 \mathrm{~mm}$ diâm., entrenós regulares, 1,2-1,5 mm, escamas basais $1,5-2 \mathrm{~mm}$ compr.; caule ereto curto, 1-2,4 mm compr., entrenós ca. 0,5 mm. Filotaxia alterna. Folha peciolada, pecíolo ereto, $5-8 \mathrm{~mm}$ compr.; oblonga-obovada, 10-18 mm compr., 3-6 mm larg., ápice obtuso, base acuneada, semicraspedródoma, margem serrilhada, espinhos unicelulares inconspícuos; estípulas ausentes; escamas intravaginais plicadas, 3-4,2 $\mathrm{mm}$ compr., ápice retuso, base amplexicaule, margem serrilhada. Inflorescência cimosa formada por uma flor estaminada e uma pistilada, cobertas por duas brácteas sobrepostas, 3-4 mm compr.; bráctea ovada, plicada, hialina, quilha serrilhada. Flor díclina, séssil, monoclamídea, trímera, submersa; sépala ovada, hialina, ca. 1,5 mm. Flor estaminada com um estame, $1,5 \mathrm{~mm}$ compr. Flor pistilada com ovário súpero, 1,5-1,7 mm compr., tricarpelar, unilocular, pluriovular, 3 estiles e estigmas distintos. Fruto globoso membranoso, 2,8-3,3 mm compr., 2,7-3 mm larg., rostro ca. $1 \mathrm{~mm}$. Semente ovada, testa reticulada.

Material examinado: Barroquinha, braço do rio Timonha, 19.I.2013, J. Umezaki (EAC 53504). Icapuí, Praia da Peroba, 23.VII.2013, P.B.M. Carneiro (EAC 57296) .

Material adicional examinado: BRASIL. BAHIA: Saubara, formações recifais do infralitoral, 24.IV.2002, A. Amado-Filho (RB 464103). Ilha de Itaparica, Praia de Manguinhos, 5.III.1973, A.G. Pedrini 67 (RB 163309). 

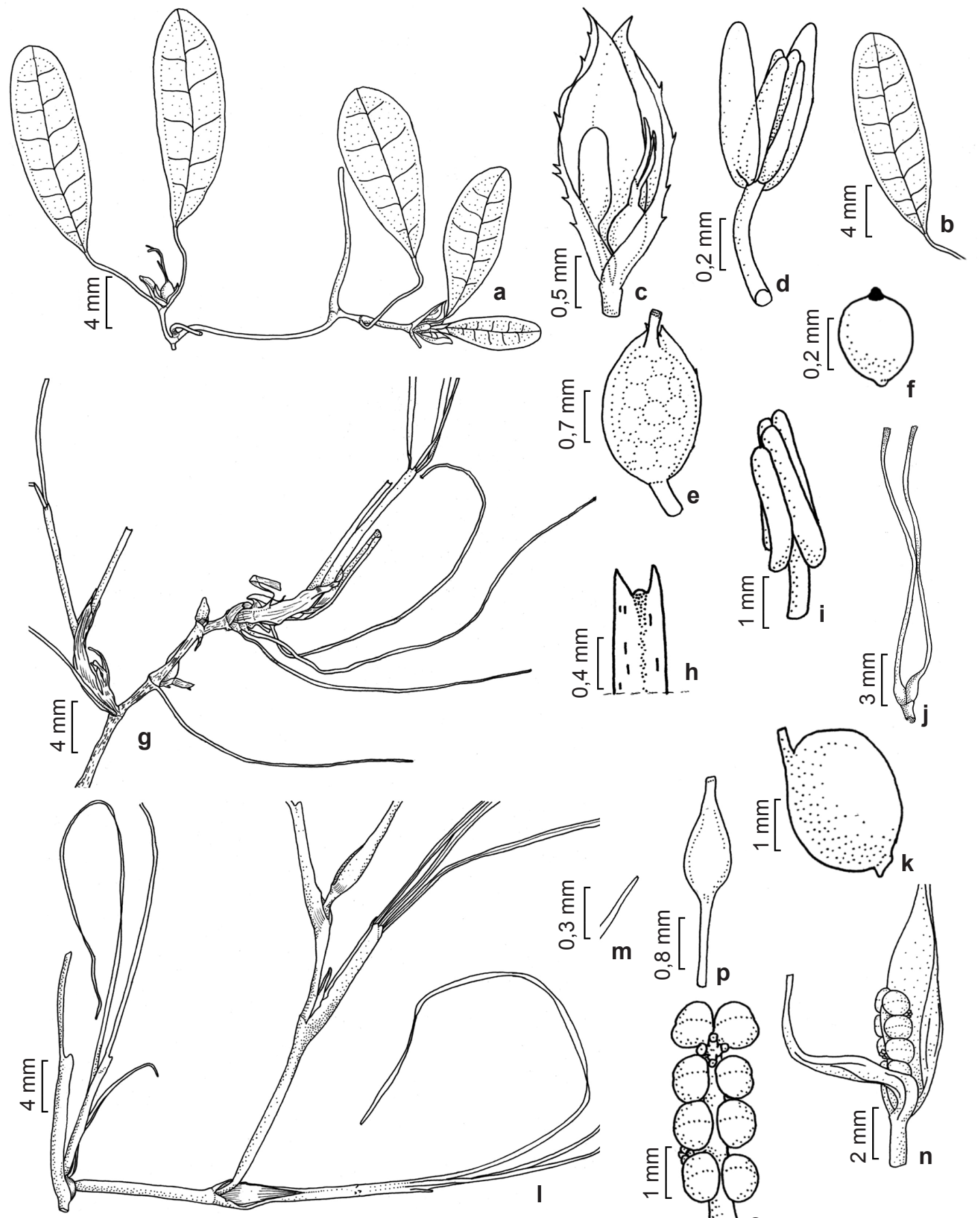

Figura 4 - a-f. Halophila decipiens - a. hábito; b. folha; c. flores feminina e masculina envoltas por brácteas; d. flor masculina; e. fruto envolto por brácteas; f. semente. g-k. Halodule wrightii - g. hábito; h. ápice foliar; i. flor masculina; j. flor feminina; k. fruto. 1-p. Ruppia maritima - 1. hábito; m. ápice foliar; n.inflorescência envolvida por brácteas; o. inflorescência evidenciando anteras laterais e carpelos centrais; p. fruto com rostro. [a-f. P.B.M. Carneiro (EAC 57296); g-k. H.H.S. Gonzalez 43; 1-p. S. Rabay (EAC 48929)].

Figure 4 - a-f. Halophila decipiens - a. habit; b. leaf; c. staminate and pistillate flowers; d. staminate flower; e. fruit envolved by bracts; f. seed. g-k. Halodule wrightii - g. habit; - leaf apex; i. staminate flower; j. pistillate flower; k. fruit. 1-p. Ruppia maritima - 1. habit; $\mathrm{m}$. leaf apex; $\mathrm{n}$. inflorescence involved by bracts; o. inflorescence showing lateral anthes and carpels in central position; $\mathrm{p}$. fruit with rostrum. [a-f. P.B.M. Carneiro (EAC 57296); g-k. H.H.S. Gonzalez 43; 1-p. S. Rabay EAC (48929)]. 
Halophila decipiens possui distribuição pantropical, ocorrendo nos Oceanos Pacífico, Índico e Atlântico (Short et al. 2001). Segundo BFG (2015), no Brasil a espécie está presente no estado do Rio de Janeiro e no litoral da Região Nordeste, desde a Bahia ao estado do Ceará. Na Região Nordeste, as populações de $H$. decipiens foram descritas apenas na faixa litorânea entre os estados da Bahia e do Rio Grande do Norte, sendo apenas recentemente indicada para a costa cearense (Fig. 1: A1, E8 e E9). Dentre as fanerógamas marinhas, as populações de $H$. decipiens podem ocupar faixas costeiras de até $85 \mathrm{~m}$ de profundidade, sendo consideradas as de ocorrência mais profunda (Oliveira-Filho et al. 1983).

6. Cymodoceaceae Vines, Stud. Text-book bot 2:553. (1895), nom.cons.

Plantas dioicas, herbáceas marinhas, submersas, enraizadas. Raízes adventícias na região nodal caulinar. Caule dimórfico, rizomatoso horizontal com escamas foliares e ereto curto, entrenós regulares. Filotaxia alterna dística. Folha simples, paralelinérvea, margem lisa, bainha aberta; lígula presente na conexão com a lâmina; estípulas comumente ausentes; escamas intravaginais escamiformes axilares. Inflorescência cimosa ou reduzida a uma flor solitária. Flores díclinas, aclamídeas, envolvidas por brácteas. Flor masculina com 2 estames, unido pelo filete, anteras rimosas. Flor feminina dialicarpelar, ovário súpero, bicarpelar, unilocular, uniovulado, cada carpelo com um longo estilete único ou ramificado formando 2-3 estigmas filiformes na porção distal. Fruto indeiscente, aquênio ou drupa.

7. Halodule Endl. Gen. Pl. [Endlicher] Suppl. 1: 1368. 184

7.1. Halodule wrightii Aschers. Sitzber. Ges. Naturf. Fr. Berlin p. 19,1868. Fig . 4g-k

Plantas dioicas, herbáceas marinhas, submersas, enraizadas. Caules dimórficos, rizoma cilíndrico, 0,3-1 mm diâm., entrenós 9-16 mm compr.; escamas basais $3-5 \mathrm{~mm}$ compr.; caule ereto curto, $1 \mathrm{~mm}$ compr., entrenós ca. $0,2 \mathrm{~mm}$. Filotaxia alterna. Folha lanceolada, 3,5-6,5 $\mathrm{cm} \times 0,3-0,5$ $\mathrm{mm}$ compr., ápice bicúspide à tricúspide, base truncada, margem lisa, nervuras paralelódromas, nervura central geralmente excurrente num espinho apical e nervuras laterais inconspícuas comumente finalizando em dois ápices agudos laterais, geralmente mais longos que o espinho mediano, segmentos entre os apêndices apicais levemente côncavos, por vezes finalizando em serrilhas irregulares; bainha foliar $22 \mathrm{~mm}$ compr.; escamas intravaginais escamiformes axilares inconspícuas. Flores díclinas, aclamídeas, solitárias, axilares, avermelhadas devido à presença de tanino. Flor estaminada pedicelada, pedicelo $1 \mathrm{~cm}$ compr.; com um estame de anteras de tamanhos diferentes e unidas pelo filete, antera inferior $4 \mathrm{~mm}$ compr. e superior $5 \mathrm{~mm}$ compr. Flor pistilada 1,2-2 mm compr., ovário obovado ligeiramente comprimido, estilete lateral ou terminal $0,7-1,5 \mathrm{~mm}$ compr., indiviso. Fruto drupa, 2-2,5 mm compr., rostro curto lateral persistente. Semente elipsoides, $2 \mathrm{~mm}$ $\times 1,8 \mathrm{~mm}$, sementes reticuladas.

Material examinado: Camocim, Ilha do Amor, 9.IV.2012, S. Rabay (EAC 52734); Paracuru, Praia Redonda, 16.II.2012, H.H.S. Gonzalez 43 (EAC). Icapuí, Praia da Requenguela, 2.VI.2012, H.H.S. Gonzales 44 (EAC); Praia de Barrinhas, Banco dos Cajuais, 11.X.2011, fl.e fr., H.H.S Gonzalez 33 (EAC). Jijoca de Jericoacoara, Praia de Jericoacoara, 13.XII.2014, L.Q. Matias 731 (EAC).

Halodule wrightii encontra-se ao longo da faixa litorânea das regiões tropicais e subtropicais (Oliveira-Filho et al. 1983), possuindo distribuição espacial ao longo da faixa tropical do Oceano Atlântico. Segundo BFG (2015), populações de $H$. wrightii encontram-se distribuídas ao longo da costa litorânea das regiões Nordeste e Sudeste do Brasil. Para a Região Nordeste existem registros de populações para os estados do Ceará, Alagoas, Bahia, Paraíba, Pernambuco e Rio Grande do Norte. No Ceará, $H$. wrightii é a única espécie do gênero registrada, ocorrendo ao longo da costa litorânea cearense, desde a cidade de Camocim (litoral oeste) à Icapuí (litoral leste) (Fig. 1: A2, A3, B5, C6, C7, D8, E8 e E9).

8. Ruppiaceae Horan., Prim. Lin. Syst. Nat. 46. (1834)

Plantas monoicas, herbáceas de água doce ou salobra, submersas enraizadas. Raízes adventícias na região basal caulinar. Caule dimórfico, rizomatoso horizontal com escamas foliares e ereto curto, entrenós regulares, ramificação monopodial, tornando simpodial na floração. Filotaxia alterna a suboposta. Folhas simples, lineares, ápice agudo a truncado, margem lisa a serrilhada, uninérveas, bainha aberta tubular; lígula ausente; estípulas ausentes; escamas intravaginais axilares inconspícuas. Inflorescência espiciforme axilar, pedúnculo alongando na antese elevando as flores. Flores monóclinas, aclamídeas, submersas; estames 2, sésseis, livres, anteras rimosas; ovário súpero, 
$(2-) 4(-16)$ carpelar, dialicarpelar, unilocular, uniovulado, circundado pelas anteras, séssil na antese tornando estipitado no fruto. Fruto drupa arredondada com longo rostro. Semente elípticas, testa ornamentda.

9. Ruppia L. - Sp. Pl. 1: 127. 1753

9.1. Ruppia maritima L. Sp. Pl., p. 127, 1753.

Fig. 41-p

Plantas monoicas, herbáceas de água doce ou salobra. Rizoma $0,8-1 \mathrm{~mm}$ diâm, entrenós 5-10 mm compr.; caule vertical cilíndrico, ca. 0,5 mm compr., 1,5-2 mm diâm. Filotaxia alterna a suboposta pelo encurtamento dos entrenós. Folhas lineares, 4-6 cm, 0,3-0,5 mm, ápice agudo, serrilhado, base truncada, uninérveas, bainha $1-1,5$ $\mathrm{cm}$ compr. Inflorescência espiciforme formada por 2 flores; pedúnculos 0,6-20 mm comp. na antese. Flores monóclinas, aclamídeas, submersas; estames 2, sésseis, 0,8-1 mm compr.; ovário tetracarpelar, 0,5-1 mm compr., sésseis na antese tornando estipitado no fruto. Fruto drupóide dorsalmente arredondado, 1- $2 \mathrm{~mm}$ comp., 1-1,5 $\mathrm{mm}$ largura, rostro 8-14 $\mathrm{mm}$. Semente ovada, testa reticulada. Material examinado: São Gonçalo do Amarante, estuário do Rio Maceió, 20.XI.2010, S. Rabay (EAC 48929).

Material adicional examinado: BRASIL. ALAGOAS: Santa Luzia do Norte, área do complexo estuarino lagunar Mundaú-Manguaba, 11.VII.1998, M.N. Rodrigues 1247 (ASE). BAHIA: Salinas da Margarida, viveiros de camarões da PESCON, 6.XII.1984, M.L. Guedes (ALCB 15162).

Ruppia maritima apresenta distribuição global cosmopolita, ao longo da faixa litorânea da maioria dos continentes (Stevens 2001). Para o Brasil, R. marítima é a única espécie do gênero Ruppia e da família Ruppiaceae registrada no país (Oliveira-Filho 1983). BFG (2015) mostrou que esta espécie possui uma ampla distribuição ao longo do litoral brasileiro, abrangendo estados das regiões Nordeste (Ceará, Alagoas, Bahia, Pernambuco e Piauí), Sudeste (Espírito Santo, Rio de Janeiro, São Paulo) e todos os estados da Região Sul. No Ceará, a ocorrência de $R$. marítima foi registrada para alguns municípios do litoral oeste cearense como São Gonçalo do Amarante (Fig. 1: B5 e C6), em locais de ambiente estuarino. Este padrão de ocupação de águas costeiras estuarinas por populações de Ruppia foi descrito por OliveiraFilho et al. (1983) para o Brasil, não havendo registro de indivíduos em áreas de salinidade mais acentuada, porém sendo indicada a ocorrência em lagoas rasas interdunares.

\section{Agradecimentos}

Agradecemos ao Conselho Nacional de Desenvolvimento Científico e Tecnológico (CNPqSisbiota), o apoio financeiro e a M. Sc. Marcelo Teles, a elaboração do mapa georeferenciado.

\section{Referências}

APG IV - Angiosperm Phylogeny Group (2016) An update of the Angiosperm Phylogeny Group classification for the orders and families of flowering plants: APG IV. Botanical Journal of the Linnean Society 181: 1-20.

BFG - The Brazil Flora Group (2015) Growing knowledge: an overview of seed plant diversity in Brazil. Rodriguésia 66: 1085-1113.

Ceska A (1986) More on technique for collecting aquatic and marsh plants. Annals of the Missouri Botanical Garden 73: 825-827.

Chen LY, Chen JM, Gituru RW \& Wang QF (2012) Generic phylogeny, historical biogeography and character evolution of the cosmopolitan aquatic plant family Hydrocharitaceae. BioMed Central Evolutionary Biology 12: 1-12.

Cook CDK \& Urmi-König K (1983) A revision of the genus Limnobium including Hydromystria (Hydrocharitaceae). Aquatic Botany 19: 73-96.

Cook CDK \& Urmi-König K (1984) A revision of the genus Egeria (Hydrocharitaceae). Aquatic Botany 19: 73-96.

Cook CDK (1985) A revision of the genus Apalanthe (Hydrocharitaceae). Aquatic Botany 21: 157-164.

Cook CDK (1996) Aquatic plant book. SPB Academic Publ., Amsterdam. 228p.

Cook CDK (1998) Hydrocharitaceae. In: Kubitzki K (ed.). The families and genera of vascular plants. Flowering plants monocotyledons Alismatanae and Commelinanae (except Graminae). Vol. 4. Springer-Verlag, Berlin. Pp. 11-15.

Dahlgren RMT \& Rasmussen FN (1983) Monocotyledon evolution: characters and phylogenetic estimation. Evolution Biology 16: 255-395

Dahlgren RMT, Clifford HT \& Yeo PF (1985) The families of the monocotyledons. Springer-Verlag, Berlin. 501p.

Den Hartog C \& Kuo J (2006) Taxonomy and biogeography of seagrass. In: Larkum A, Orth RJ \& Duarte C (eds.) Seagrasses: biology, ecology and conservation. Springer, Dordrecht. Pp. 1-23.

Haynes RR (1977) The Najadaceae in the Southeastern United States. Journal of the Arnold Arboretum 58: 161-171.

Haynes RR (1984) Techniques for collecting aquatic and marsh plants. Annals of the Missouri Botanical Garden 71: 229-231. 
Haynes RR \& Holm-Nielsen LB (2001) The genera of Hydrocharitaceae in the Southeastern United States. Harvard Papers in Botany 5: 201-275.

INPI - The International Plant Names Index (2015) Disponível em $<$ http://www.ipni.org $>$. Acesso em 11 junho 2015.

Koehler S \& Bove CP (2011) Hydrocharitaceae from central Brazil: a new species of Egeria and a note on Apalanthe granatensis. Novon 11: 63-66.

Kuo J \& den Hartog D (2001) Seagrass taxonomy and identification key. In: Short FT \& Coles RG (eds.) Global seagrass research methods. Elsevier, Amsterdam. Pp. 31-50.

Les DH, Gravin DK \& Wimpee CF (1993) Phylogenetic studies in the monocot sybclass Alismatidae: evidence for a reappraisal of the aquatic order Najadales. Molecular Phylogenetic and Evolution 2: 304-314.

Les DH, Moody ML \& Soros CL (2006) A reappraisal of phylogenetic relationships in the monocotydelon family Hydrocharitaceae (Alimastidae). Aliso 22: 211-230.

Lowden RM (1986) Taxonomy of the genus Najas L. (Najadaceae) in the Neotropics. Aquatic Botany 24: 147-184.

Lowden RM (1992) Floral variation and taxonomy of Limnobium L.C. Richard (Hydrocharitaceae). Rhodora 94: 111-134.

Matias LQ \& Sousa DJL (2011) Alismataceae no estado do Ceará, Brasil. Rodriguésia 62: 887-900.

Petersen G, Seberg O, Cuenca A, Stevenson DW, Thadeo M, Davis JI, Graham S \& Ross TG (2016)
Phyogeny of the Alismatales (Monocotyledons) and the relationship of Acorus (Acorales?). Cladistics 32: 141-159.

Okada H (2001) Scientific achievements of IGCP-350 "Environmental and Biological Change in East and South Asia during the Cretaceous": an overview. Developments in Palaeontology and Stratigraphy 17: 243-255.

Oliveira-Filho EC, Pirani JR \& Giulietti AM 1983. The Brazilian sea-grasses. Aquatic Botany 16: 251-267.

Ross TG, Barret GF, Gomez MS, Lam VKY, Henriquez CL, Les DH, Davis J, Cuenca A, Petersen G, Seberg O, Thdeo M, Givnish TJ, Conran J, Stevenson DW \& Graham SW (2016) Platid phylogenomics and molecular evolution of Alismatales. Cladistics 32: 160-178.

Short FT, Coles RG \& Pergeny-Martini C (2001) Global seagrass distribuition. In: Short FT \& Coles RG (eds.) Global seagrass research methods. Elsevier, Amsterdam. Pp. 5-30.

Stevens PF (2001 onwards). Angiosperm Phylogeny Website. Version 9. Disponível em <http://www. mobot.org/MOBOT/research/APweb/> Acesso em 13 fevereiro 2015.

Thiers B [continuously updated] Index Herbariorum: a global directory of public herbaria and associated staff. New York Botanical Garden's Virtual Herbarium. Disponível em <http://sweetgum.nybg. org/ih/>. Acesso em 18 junho de 2013.

Vu Khuc D (2000) Cretaceous environments in Viet Nam, Laos and Camboja. Developments in Palaeontology and Stratigraphy 17: 201-205. 